\title{
ENGLISH VERSION: PATHOPHYSIOLOGIC MECHANISMS OF THE INFLUENCE OF TISSUE RESPIRATION ENZYMES ON THE MITOCHONDRIAL FUNCTION IN PATIENTS WITH CHRONIC HEPATITIS C
}

Bagmut I.Y., Gramatiuk S.M.

Kharkiv Medical Academy of Postgraduate Education

Department of Clinical Pathophysiology, Topographic Anatomy and Operative Surger, Kharkiv, Ukraine

Studies conducted over several decades in the field of pathophysiological mechanisms of hepatocyte mitochondria have usually been directed to functional studies of isolated mitochondria in the absence of $A D P$. In many cases, researchers used data to calculate parameters, including the respiratory rate or the amount of ADP consumed for each amount of oxygen used. However, so far, little is known about how the virus can survive in a highly oxidizing environment, given that oxidative stress is such an outstanding clinical feature that is associated with infection with the hepatitis $C$ virus. In our opinion, adaptation to oxidative stress is a pathophysiological mechanism for the survival of the virus. The objective is to research mechanisms of energy supply disturbance as a mechanism of damage to cells in patients with chronic viral hepatitis C. The $62 \mathrm{HCV}+$ patients and 24 healthy controls were enrolled in the present cross-sectional study. The patients were selected on the basis of their stable clinical condition over the past 3 months. The HCV infection was diagnosed by the positivity of anti-HCV and HCV-RNA for at least 6 months of period. Mitochondrial integrity was assessed by cytochrome C release using a commercial kit (Cytochrome C Oxidase Assay Kit, Sigma-Aldrich, St. Louis) indicating a mean of $96 \%$ intact mitochondria. Intrinsic NADH fluorescence was monitored in isolated mitochondria as a marker of the mitochondrial NADH redox state. Mitochondrial division is a key determinant of mitochondrial quality control, and HCV modulates these key processes in the adaptation to cellular physiological perturbations associated with infection to promote viral persistence. Mitochondrial division is not invariably associated with cell death but can also protect cells from death induced by oxidative stress and $\mathrm{Ca}^{2+}$-dependent apoptotic stimuli. The mechanism by which enzymes for energy metabolism suppress the replication of the hepatitis $C$ virus is not yet clear, but it probably includes calcium and dissociation of the mammalian replication complex. A detailed understanding of the mechanism by which energy enzymes suppress the replication of HCV infection require additional research.

Key words: hepatitis C, NAD/NADH2, mitochondrial fission.

\section{Introduction}

The hepatitis $\mathrm{C}$ virus affects $3 \%$ of the world population and causes a clinically important disease [1, 2]. Hepatitis $C$ virus is recognized as a major factor in fibrosis and cirrhosis development. Parenchymal damage of cell membranes may lead to metabolic disorders, which plays a major role of liver fibrosis in formation of hepatitis $C$ [2-3]. The researches dating back to several decades have usually been carried out in functional studies of isolated mitochondria in the absence of ADP [1]. In many cases, investigators have used the data to calculate parameters including the respiratory control ratio or the amount of ADP consumed per amount of oxygen utilized [1]. Such studies have been widely applied to describe mitochondrial function as affected by a myriad of physiologic or pathophysiologic states.

The components of metabolomic function of hepatocytes: mitochondrial function, respiratory states and endogenic intoxication have been assessed in the past by different methods designed to regenerate ADP for phosphorylation. These include the use of creatine, creatine kinase [2-4], ATPase with excess ATP [2, 5-7], and ratio $\mathrm{NAD}^{+} / \mathrm{NADH}_{2}$, glucose/hexokinase [4, 8].

Most of these studies were directed at liver mitochondria. HCV establishes a chronic infection in the face of an active immune response and the host oxidative defense. However, little is known about how the virus can survive in a highly oxidative environment given that oxidative stress is such a prominent clinical feature associated with hepatitis C infection [6-12]. Adaptation to oxidative stress is key to virus survival.

The objective is to research mechanisms of energy supply disturbance as a mechanism of damage to cells in patients with chronic viral hepatitis $\mathrm{C}$.

\section{Material and Methods}

$62 \mathrm{HCV}+$ patients and 24 healthy controls were enrolled in the present cross-sectional study. The patients were selected on the basis of their stable clinical condition over the past 3 months.

The study protocol was carried out in accordance with the Helsinki Declaration as revised in 1989. All subjects were informed about the study and the written consent was obtained from each one.

$\mathrm{HCV}$ infection was diagnosed by the positivity of antiHCV and HCV-RNA for at least 6 months period.

Exclusion criteria

History of alcohol abuse, smoking habit, pregnancy, and antioxidant use, fish-oil or iron supplement in the previous month, receiving antiviral and/or interferon therapy, uncontrolled elevated blood pressure, serum total bilirubin level higher than $2 \mathrm{mg} / \mathrm{dL}$, concomitant chronic hepatitis B or other well-known liver diseases such as metabolic or autoimmune disorders and various infectious states of the liver, human immune deficiency virus infection, diabetes mellitus, chronic respiratory insufficiency, rheumatoid arthritis, cirrhosis, or malignant tumor.

Virological studies

Anti-HCV was assayed by micro particle ELISA method (Anti-HCV ELISA Kit, Diagnostic Automation/Cortez Diagnostics, Inc., USA). HCV-RNA was determined using real time polymerase chain reaction (RTPCR) method (RoboGene $₫$ HCV RNA Quantification Kit, Analytik Jena) in BioRad ICycler. Upper and lower detection limit $(68 \mathrm{lU} / \mathrm{ml})$.

Preparation of erythrocytes mitochondria

* To cite this English version: Bagmut I.Y., Gramatiuk S.M. Pathophysiologic mechanisms of the influence of tissue respiration enzymes on the mitochondrial function in patients with chronic hepatitis C. // Problemy ekologii ta medytsyny. - 2018. - Vol 22, № 1-2. - P. 7-10. 
Erythrocytes were washed twice in phosphatebuffered saline (145 mM NaCl, $5 \mathrm{mM} \mathrm{NaPi}$, and $1 \mathrm{mM}$ EDTA, pH 7.4) and white cells were removed by filtration through cellulose [9]. Total erythrocytes mitochondria were prepared by differential centrifugation and purification on Percoll [10]. Mitochondrial integrity was assessed by cytochrome $C$ release using a commercial kit (Cytochrome C Oxidase Assay Kit, Sigma-Aldrich, USA).

The study of the ADP/ATP ratio using the ADP/ATP Ratio Assay set is a simple and direct procedure for measuring ADP and ATP levels in cells to determine apoptosis, necrosis and cell proliferation. The analysis involves two stages. In the first stage, the working reagent lyses cells to release ATP and ADP. In the presence of luciferase, ATP reacts immediately with the substrate D-Luciferin to produce light. The intensity of light is a direct indicator of intracellular ATP concentration.

Luciferase

$\mathrm{ATP}+\mathrm{D}-$ Luciferin $+\mathrm{O}_{2}$--------> oxyluciferin+AMP+PPi $+\mathrm{CO}_{2}+$ light

In the second stage, ADP is converted to ATP through an enzyme reaction. This newly formed ATP then reacts with the D-luciferin as in the first step. The second light intensity measured represents the total ADP and ATP concentration in the sample.

Registration of $\mathrm{H}_{2} \mathrm{O}_{2}$ products by mitochondria. The production of $\mathrm{H}_{2} \mathrm{O}_{2}$ was estimated by ATP production as described by $\mathrm{Yi}$ Li [14]. Fluorescence was measured and a quantitative estimate was made [13]. In total, in a sample containing $1.5 \mathrm{mM}$ cytochrome $\mathrm{C}$ or ferricitohrom $\mathrm{C}$, $0.5 \mathrm{ml}$ of isolated cells were added to HBSS (approximately $5 \times 10^{6}$ cells per milliliter).

Measurement of hydrogen peroxide in mitochondria. The production of hydrogen peroxide was measured fluorometrically using Amplex Red dye (Eugene, USA) in combination with horseradish. In these experiments, the incubation medium was supplemented with $1 \mathrm{~L}$ of ample red, $5 \mathrm{ml}$ of horseradish peroxidase and $40 \mathrm{ml}$ of $\mathrm{Cu}$, superoxide dismutase $\mathrm{Zn}$. The presence of superoxide dismutase prevents the automatic oxidation of Amplex Red, which prevents the quantitative assessment of low $\mathrm{H}_{2} \mathrm{O}_{2}$ production rates. The production of $\mathrm{H}_{2} \mathrm{O}_{2}$ in mitochondrial

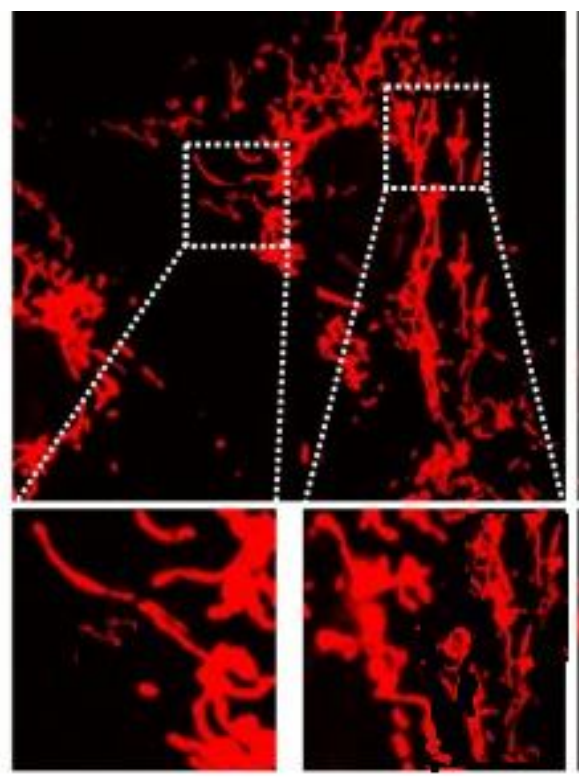

Healthy cells suspensions was recorded as an increase in the fluorescence of the dye at $585 \mathrm{~nm}$, with a wavelength of excitation of $550 \mathrm{~nm}$. The dye reaction was calibrated by successive addition of known amounts of hydrogen peroxide solution or continuous infusion of $\mathrm{H}_{2} \mathrm{O}_{2}$ solution at 100$1000 \mathrm{pmol} / \mathrm{min}$. The concentration of commercial $30 \%$ solution of $\mathrm{H}_{2} \mathrm{O}_{2}$ was calculated from optical absorption of light at $240 \mathrm{nM}$ ); The stock solution was diluted to $100 \mathrm{ml}$ with deionized water and immediately used for calibration.

Respiration and membrane potential methods by $\mathrm{Yi} \mathrm{Li}$ [14] in modification.

Mitochondria $(0.05 \mathrm{mg} / \mathrm{ml})$ were incubated at $37^{\circ} \mathrm{C}$ in $2 \mathrm{ml}$ of ionic respiratory buffer $(105 \mathrm{mM} \mathrm{KCl}, 10 \mathrm{mM}$ $\mathrm{NaCl}, 5 \mathrm{mM}$ Na2HPO4, $2 \mathrm{mM} \mathrm{MgCl}$, $10 \mathrm{mM}$ HEPES $\mathrm{pH}$ 7.2, $1 \mathrm{mM}$ EGTA, $0.2 \%$ defatted BSA) with $5 \mathrm{U} / \mathrm{ml}$ hexokinase (Worthington Biochemical), and $5 \mathrm{mM} 2-$ deoxyglucose. A tetraphenylphosphonium standard curve was performed in each run by adding tetraphenylphosphonium chloride at concentrations of $0.25,0.5,0.75$, and $1 \mu \mathrm{M}$ prior to the addition of mitochondria to the chamber.

Statistical Analysis

An independent (unpaired) Student's t-test (twotailed) was chosen to test the significance of differences among means of small " $n$ " sample sets, using the StatGraphics Plus 3.0 package.

\section{Results and discussion}

There were no statistically significant differences between the groups with respect to age and gender $(p>$ $0.05)$. No correlation was observed between ALT and HCV-RNA level in HCV-infection patients ( $p>0.05)$.

HCV-infection induces endogenic intoxication and oxidative stress salters which causes mitochondrial dysfunction and hepatocytes damage. The HCV-infected cells displayed fragmented mitochondria distinct from non-infected cells, in which the typical tubular mitochondrial network has been observed as indicative of normal healthy cells (Figure 1).

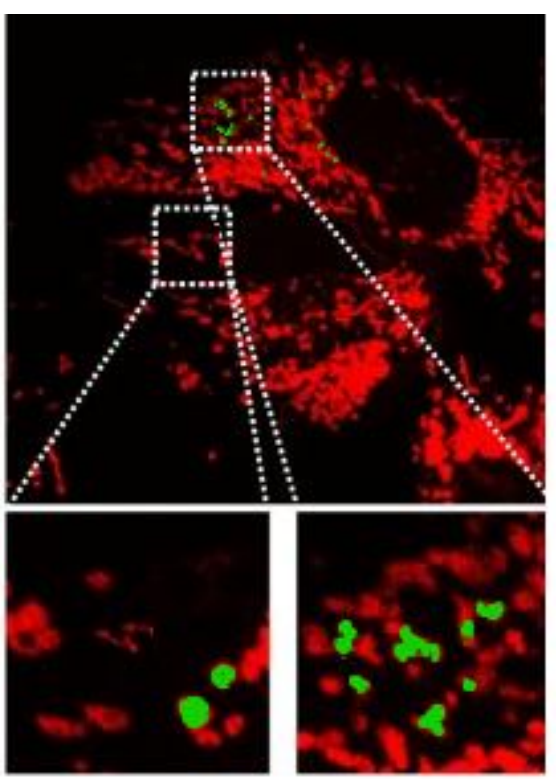

HCV-inferected cells

Figure 1. The mitochondrial HCV-infected and healthy cells. 
In the control group, we observed a gradual increase in the $\mathrm{O}_{2}$ index when added to the ADP solution. However, when compared with a group of patients with chronic viral hepatitis $\mathrm{C}$, it was found that $\mathrm{O}_{2}$ values were significantly $(p<0.05)$ higher in patients with HCV infection.

The total levels of ATP and ADP secreted the patients with hepatitis $C$ virus was $2.25 \pm 0.35$ nmoles and
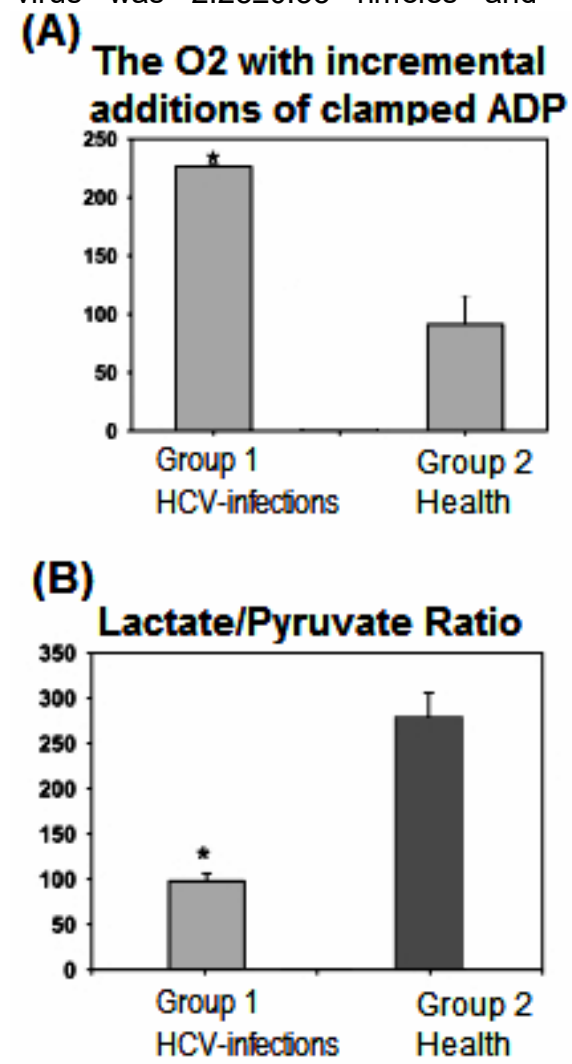

$3.40 \pm 0.45$ nmoles. The ratio of ATP to ADP, secreted from platelets upon activation, was $1: 1.60$ respectively (Figure $2(A)$ ). Mitochondrial dynamics and quality control are closely associated with cellular metabolic alterations and ATP levels. To investigate whether inhibition in HCV secretion is a result of reduction in cellular ATP levels, we determined the total ATP levels and rate of glycolysis, an alternative mode of ATP generation..
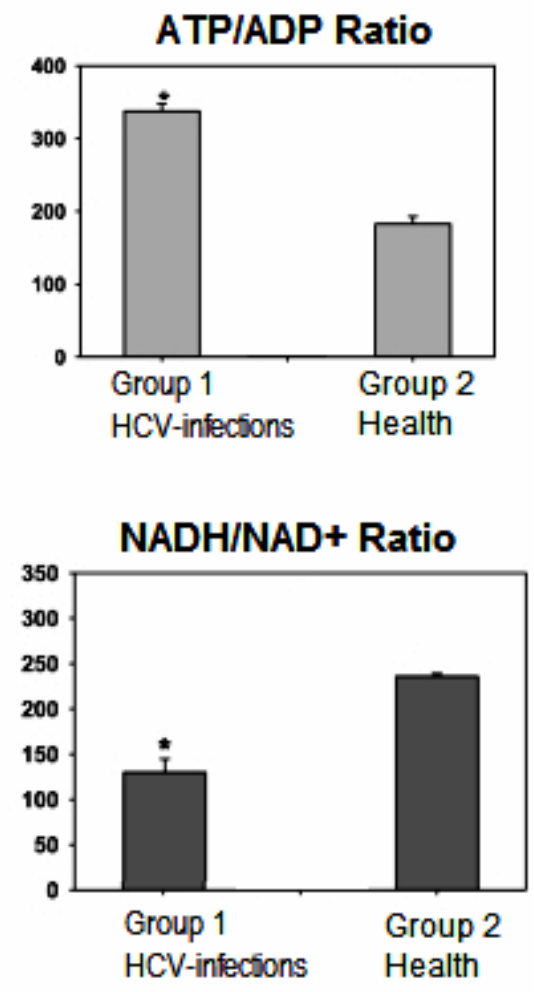

Figure 2. Inhibition of mitochondrial division and mitochondrial function. A- O2 with incremental additions of clamped ADP and ATP/ADP ratio, $B$ - Lactate/Pyruvate ratio, NADH/NAD+ ratio..

To detect bioenergetics changes, we examined the ratio of pyruvic acid and lactate as markers of carbohydrate metabolism oxidative stage (the ratio of aerobic and anaerobic phases), and $\mathrm{NAD}^{+}$and $\mathrm{NADH}_{2}$ levels as mandatory participants of oxidation-reduction reactions and regulators of cell metabolism. Decreased $\mathrm{NADH}_{2}$ index $(0.002 \pm 0.0001 \mathrm{mmol} / \mathrm{l})$ was determined in comparison with control group $(0.01+0.0005 \mathrm{mmol} / \mathrm{l})$. The $\mathrm{NAD}^{+}$concentration $(0.494 \pm 0.03 \mathrm{mmol} / \mathrm{l})$ was significantly $(P<0.05)$ increased in patients with $\mathrm{HCV}$-infection in comparison with normal content, respectively (Figure 2 (B)). The NADH fluorescence did not change at low ADP in patients with HCV-infection. The production of reactive oxygen species (ROS) was very high in HCV-infections. An increased content of oxidized nicotinamide coenzymes was detected in patients with chronic hepatitis C.

Lactate and pyruvate parameters study has found the following. In patients of Group 1 lactate indexes exceeded the parameters of control group and amounted $2.12 \pm 0.23$ and $1.89 \pm 0.45 \mathrm{mmol} / \mathrm{l}$ in comparison with control value $(1.56 \pm 0.235 \mathrm{mmol} / \mathrm{l})$. Pyruvate serum indexes were significantly lower than in the control group $(0.056 \pm 0.011 \mathrm{mmol} / \mathrm{l})$ and composed for patients with HCV-infections $0.031 \pm 0.012 \mathrm{mmol} / \mathrm{l}$, respectively (Figure 2 (B)). Pyruvate, which re-oxidizes cytosolic NADH to
$\mathrm{NAD}+$, completely abrogated the increases in $\mathrm{HCV}$ replication.

\section{Conclusion}

Mitochondrial division is a key determinant of mitochondrial quality control, and HCV modulates these key processes in the adaptation to cellular physiological perturbations associated with infection to promote viral persistence. Mitochondrial division is not invariably associated with cell death but can also protect cells from death induced by oxidative stress and $\mathrm{Ca}^{2+-}$ dependent apoptotic stimuli. The mechanism by which enzymes for energy metabolism suppress the replication of the hepatitis $C$ virus is not yet clear, but it probably includes calcium and dissociation of the mammalian replication complex. A detailed understanding of the mechanism by which energy enzymes suppress the replication of HCV infection requires additional research.

\section{References}

1. Kim S.J., Syed G.H., Siddiqui A. Hepatitis $C$ virus induces the mitochondrial translocation of Parkin and subsequent mitophagy. // PLoS Pathog. - 2013. - T. 9(3). - P.10321085.

2. Korenaga M. Hepatitis $C$ virus core protein inhibits mitochondrial electron transport and increases reactive oxygen species (ROS) production. // J Biol Chem. - 2005. - T. 280(45). - P. 37481-37488. 
ToM 22, N 1-2 2018 p.

3. Piccoli C. Hepatitis $\mathrm{C}$ virus protein expression causes calcium-mediated mitochondrial bioenergetic dysfunction and nitro-oxidative stress. // Hepatology. - 2007. - T. 46(1). P.58-65.

4. Chan D.C. Fusion and fission: Interlinked processes critical for mitochondrial health. // Annu Rev Genet. - 2012. T. 46. - P. 265-287.

5. Ushio-Fukai M. Compartmentalization of redox signaling through NADPH oxidase-derived ROS. // Antioxid Redox Signal. - 2009. - T. 11. - P. 1289-1299.

6. Berglund A. K. Nucleotide pools dictate the identity and frequency of ribonucleotide incorporation in mitochondrial DNA. / Berglund A. K., Navarrete C., Engqvist M. K., Hoberg E., Szilagyi Z.// PLoS Genet. - 2017. - T.1. 13:e1006628. 10.1371/journal.pgen.1006628.

7. Calvo S. E., Clauser K. R., Mootha V. K. MitoCarta2.0: an updated inventory of mammalian mitochondrial proteins. // Nucleic Acids Res. - 2016. - T.44. - P.1251-1257. 10.1093/nar/gkv1003.

8. Copeland W. C., Longley M. J. Mitochondrial genome maintenance in health and disease. DNA. // Rep. -2015. - T.19. - P.190-198. 10.1016/j.dnarep.2014.03.010.
9. Braverman N. E., Moser A. B. Functions of plasmalogen lipids in health and disease. // Biochim. Biophys. - 2013. T. 1822. - P. 1442-1452. 10.1016/j.bbadis.2012.05.008.

10. Brites P., Waterham H. R., Wanders R. J. Functions and biosynthesis of plasmalogens in health and disease. // Biochim. Biophys. - 2015. - T. Acta.1636. - P. 219-231. 10.1016/j.bbalip.2003.12.010.

11. Buchert R., Tawamie H., Smith C., Uebe S. A peroxisomal disorder of severe intellectual disability, epilepsy, and cataracts due to fatty acyl-CoA reductase 1 deficiency. // Am. J. Hum. Genet. - 2014. - T. 95. - P. 602-610. 10.1016/j.ajhg.2014.10.003.

12. Burdett K., Larkins L. K., Das A. K., Hajra A. K. Peroxisomal localization of acyl-coenzyme $A$ reductase (long chain alcohol forming) in guinea pig intestine mucosal cells. // J. Biol. Chem. - T. 266. - P. 12201-12206.

13. Cheng J. B., Russell D. W. Mammalian wax biosynthesis. I. Identification of two fatty acyl-Coenzyme A reductases with different substrate specificities and tissue distributions. // J. Biol. Chem. - 2004. - T. 279. - P. 3778937797. 10.1074/jbc.M406225200.

14. Xing $\mathrm{Du}, \mathrm{Yi} \mathrm{Li}$, Shu-Qun Liu Insights into protein-ligand interactions: mechanisms, models and methods // Int J Mol Sci. - 2016. - Vol.17(2). - P.144-147. 